\title{
3. The bigger picture
}

\subsection{REGIONAL, NATIONAL AND INTERNATIONAL FACTORS}

The (possible) RII performance of a university depends on the regional innovation system in which it operates. Any RII activity or pathway will be shaped and driven by a mix of local circumstances, regional infrastructures, opportunities and conditions for experimentation, knowledge creation and learning processes, and useful outputs for socio-economic development. Connectivity between universities and regional actors is a key RII parameter. Universities will tend to shape RII-creating activities and strategies based on a mixture of: interdependent inputs and processes; internal organisational characteristics and priorities; external, homogenising forces such as (inter)national HE policy frameworks and regulations; requirements and expectations from local or regional partners and stakeholder networks (Benneworth et al., 2015). Strong local links between the 'triple helix' of the higher education sector, the business sector, and government authorities is now generally seen as one of the common conditions for a successful regional innovation system, where civic sector actors can be included as part of the 'quadruple helix' configuration. ${ }^{1}$

But universities are also shaped and driven by factors beyond the local or regional environment. Think of international students, funding from national government, or global research networks. National stakeholders or international funders play a role in the core functions and strategic missions of universities, and the governance models they deploy to engage with local or regional development priorities (Goldstein, 2010; Laursen et al., 2012; Pinheiro et al., 2015). The national or international dimension may dominate over the local or regional one.

\footnotetext{
1 Theoretical and conceptual models that focus on the role of HEIs in science-innovation systems include the Mode 2 model (Gibbons et al., 1994), Triple Helix model (Etzkowitz and Leydesdorff, 1995) and Quadruple Helix model (Carayannis and Campbell, 2009; 2012). The latter model incorporates a new type of 'civic society' actors; students, consumers, citizen groups, and the general public, who interact and cooperate with the 'triple helix' of universities, business enterprises and government organisations.
} 
Although regional innovation processes are spatially embedded and geographically dependent, the underlying complex social systems are characterised by all sorts of 'push and pull' flows, interactions and interdependencies between individuals and organisations. Moreover, these relationships and connections do not stop at local or regional borders. Figure 3.1 exhibits a simplified, stylised diagram of a networked complex system, where the university's involvement in the regional innovation system interacts with the national or global environment where, for example, goals and resources for scientific research projects are set in collaboration with partners outside the local region. ${ }^{2}$ International projects or national networks may not only generate a range of regional innovation impacts, but also create spill-over effects and benefits elsewhere in the home country, in Europe, or even worldwide.

Large research universities in Europe also tend to act as 'hubs' or 'system integrators' within their local or regional knowledge infrastructures, connect-

National or international innovation systems and interaction environments

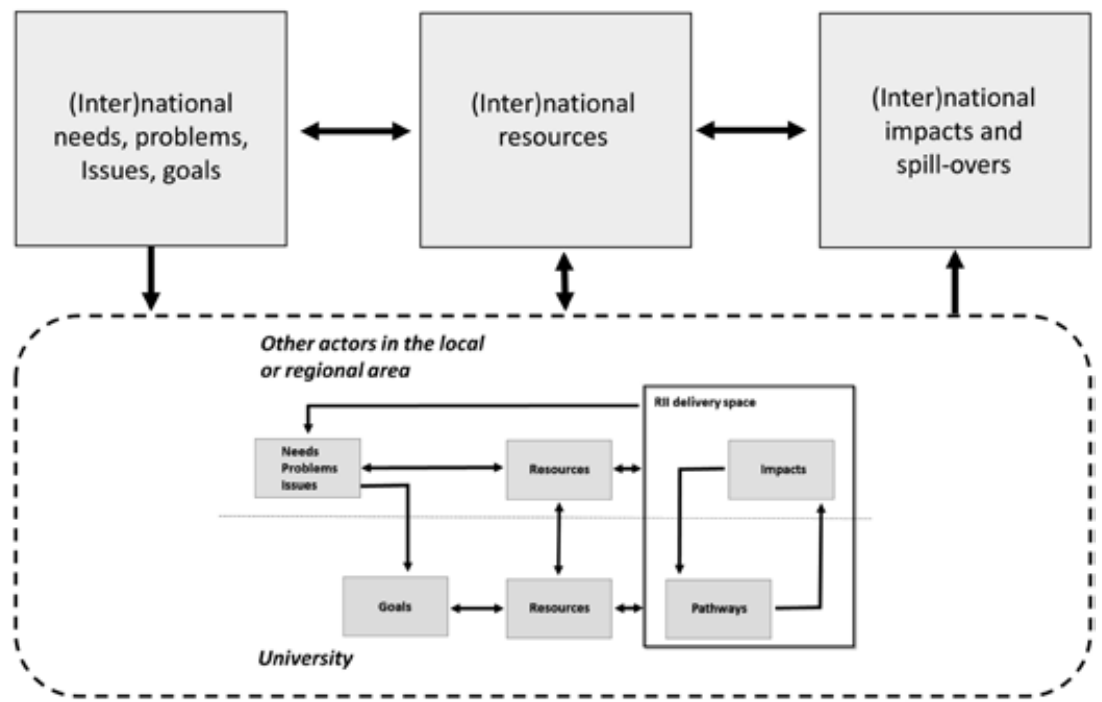

Figure 3.1 National and international dimension of a university's RII system

2 In the smallest EU Member States (such as Luxembourg and Malta), the national and regional dimension are equivalent entities in the NUTS classification system (NUTS1 and NUTS2 regions). 
ing them with the national and international levels. They attract and retain people and other resources, and all the associated services that emerge, which overall creates a more dynamic environment. This effect arises from positive agglomeration processes: in order to benefit more effectively from university resources, such as knowledge sharing with academics, R\&D-intensive business enterprises and research institutes, other higher education institutions, but also vocational training institutes are more likely to move to cities with such universities or expand their operations. Localised 'knowledge spill-overs' and economies of agglomeration are key determinants within innovation-enhancing local environments (e.g. Breschi, 2011). Universities with an industry-aligned research specialisation profile have a much higher chance of successfully engaging with the local business sector.

\subsection{THEORY OF CHANGE}

Creating impacts and spill-over effects implies noticeable change - both on the side of the cause (contributor) or the effect (recipient). Some impacts and changes occur by chance and were unintended, others are by design and desired. To determine whether or not an RII analytical framework makes any sense, as part of a policy steering mechanism, we need to develop a 'Theory of Change' (ToC) methodology. An explicit and actionable ToC can guide the design of coordinated RII policies and strategic plans, as well as the design of a customised RII analytical framework. Such a ToC states feasible goals and identifies necessary initiatives or preconditions. It also identifies the implementation of intermediate steps leading to a specific outcome that should ultimately cumulate in a series of short-term, intermediate, and longer-term RIIs. Those cause/effect chains and pathways are, ideally, explained by rationales of why one stage in the process is thought to be a prerequisite for another. ToCs specify trajectories and underlying processes that lead from resources to impacts, a road map of actions a university should take to achieve RII-related goals.

Adopting a ToC for policy guidance implies explicit steering effects. It requires organisational actors and stakeholders to specify and model the desired and anticipated impacts before they decide on forms of initiative or policy interventions to achieve those outcomes. Which raises the key question: what can be steered, and what are those targeted or expected outcomes? That depends on the perspective. Focusing on the universities, a distinction should be made between 'generic' ToCs, which apply across a range of universities, and 'institute-specific' ToCs that show how a university can organise itself to create and achieve desired changes and targeted RIIs.

Moreover, the various policy environments in which universities operate are embedded in three higher-level 'system conditions': (a) national or federal reg- 
ulatory and legal frameworks, (b) socio-economic and political structures, and (c) higher education governance systems. Each of these interconnected conditions is driven by its own needs, problems and issues that affect RII-related policy formulation and implementation. As an example of possible policy steering processes and external interventions, Figure 3.2 presents a 'generic' system-level version of the arenas, actors and actions a university could take to improve its RII performance. This particular logic model ${ }^{3}$ is 'non-linear' - it includes two explicit feedback loops ('adjustments') to capture and implement learning effects. There could in fact be many more 'minor' adjustments within and between the various steps in this process. The policy implementation will comprise funding mechanisms and resource sharing, embedding associated legislation and regulations. When looking at Europe, and the EU in particular, one can observe a wide range of policy initiatives and ToCs designed to promote regional engagement and economic development. Some of those ToCs are implicit and embedded in local 'bottom up' initiatives, others apply very explicit ToCs and are driven by (supra)national 'top down' policy interventions.

\begin{tabular}{|c|c|}
\hline Actor arena & ons \\
\hline \multirow{2}{*}{$\begin{array}{l}\text { Regional } \\
\text { development } \\
\text { policy }\end{array}$} & Policymakers and advisory bodies identify the need for (more) RII \\
\hline & $\begin{array}{l}\text { Local and regional authorities, external funders and the university identify (common) socio-economic } \\
\text { problems and needs that may result in RII }\end{array}$ \\
\hline \multirow{6}{*}{$\begin{array}{l}\text { University and } \\
\text { institutions in } \\
\text { local or } \\
\text { regional area }\end{array}$} & $\begin{array}{l}\text { University identifies its existing Rll potential, or options for capacity development, to address these } \\
\text { local or regional socio-economic issues }\end{array}$ \\
\hline & $\begin{array}{l}\text { University adopts an RII development agenda and defines organisational goals for RII delivery; the } \\
\text { university and stakeholders (public or private sector) develop a RII mission statement and success criteria }\end{array}$ \\
\hline & $\begin{array}{l}\text { University defines priorities and budget allocations for RII related initiatives or interventions; establishes } \\
\text { or strengthens its linkages and networks with local or regional partners (public or privatesector) }\end{array}$ \\
\hline & $\begin{array}{l}\text { University community engagement focuses on problem awareness, capacity building and agenda } \\
\text { alignment, where local authorities and partners may cooperate and contribute further dedicated resources }\end{array}$ \\
\hline & $\begin{array}{l}\text { University creates new RII pathways, or further develops existing pathways, specifically aimed at RII } \\
\text { delivery within the foreseeable future }\end{array}$ \\
\hline & $\begin{array}{l}\text { University and/or stakeholders conducts monitoring and assessment exercises to track chances and } \\
\text { determine (the chances of) possible Rll success or failure }\end{array}$ \\
\hline \multirow{2}{*}{$\begin{array}{l}\text { University, } \\
\text { innovation } \\
\text { systems, and } \\
\text { broader society }\end{array}$} & $\begin{array}{l}\text { University and/or stakeholders introduce adjustments, if necessary, to achieve intended short-term Rll- } \\
\text { related outcomes or longer-term objectives }\end{array}$ \\
\hline & $\begin{array}{l}\text { RII delivery space produces impacts with socioeconomic value within the regional innovation system and } \\
\text { the wider region, or derivative spill-over effects outside the local municipality, urban area or wider region }\end{array}$ \\
\hline
\end{tabular}

Figure 3.2 Hypothetical example of a university's RII-related logic model: key actors and key actions

3 Where a Theory of Change specifies and explains assumed or tested causal links between inputs, processes, outputs, outcomes and impacts, an associated 'logic model' or 'action model' describes or depicts the logical sequence of those connections or actions. 
In order to identify, classify and assess a university's RII profile, it is crucial to understand how universities may shape or affect those regional innovation systems. Supplying the ToC or logic model with relevant information on (most likely) causes and effects, entails a firm grasp of a university's RII capacity and the chances of generating RII. Organisational missions and activity profiles are key contributing factors. Over the years a significant number of studies have been conducted, mainly in Europe and the United States, on regional impacts of universities, usually the economic impact of individual universities. About 25 years ago, a study by Harvey Goldstein and his colleagues identified eight interconnected functions of modern research-active universities that may lead to regional economic development and impacts (Goldstein et al., 1995):

- creation of knowledge;

- human capital creation;

- transfer of existing knowledge and know-how;

- technological innovation;

- capital investment;

- regional leadership;

- influence on regional environment;

- knowledge infrastructure production.

Professor Goldstein and his co-worker Catharine Renault, both then at the University of North Carolina, were among the first to develop a model for RII analysis and assessment (Goldstein and Renault, 2004). In that study, which collected data on average earnings of university graduates across 312 metropolitan areas in the United States, they found that the 'research and technology creation' function generated significant knowledge spill-overs that resulted in enhanced regional economic development which would otherwise not have occurred. More importantly, they observed that this function's contribution was small compared with other functions. Which of the other functions will have a much larger regional impact is unclear. Although teaching and training (human capital creation) is a very likely candidate, conclusive empirical evidence of regional impact is still largely lacking (Valero and Van Reenen, 2019; p. 66).

Overviews and reviews of similar types of studies can for example be found in Drucker and Goldstein (2007). Several academic studies have hypothesised, or empirically unravelled the main organisational functions and associated RII resources and pathways. A host of studies and related policy reports have appeared in recent years on the regional impact of universities (e.g. Technopolis et al., 2012; Edwards et al., 2020). The EC-commissioned EUniVation study, on measuring the contribution of universities to innovation through education, proposes a number of metrics that can be used for assessing 
the (potential) economic impact of universities with regards to their teaching and training activities (European Commission, 2017a). As for the practical utility and validity, a subsequent study of three selected indicators (media appearances by staff and students, third mission policies, and budget for outreach activities) proved each of them suitable for the societal engagement functions under consideration (Benneworth and Zeeman, 2018).

The HEInnovate initiative, a parallel development in Europe, provides an indicator-based tool specifically designed for universities worldwide. It has proven to be a useful 'peer learning' tool for university management, enabling them to explore and compare their entrepreneurial and innovative potential. The online self-assessment module distinguishes eight 'areas': Leadership and Governance; Organisational Capacity; Entrepreneurial Teaching and Learning; Preparing and Supporting Entrepreneurs; Digital Transformation and Capability; Knowledge Exchange and Collaboration; The Internationalised Institution; and Measuring Impact. Each area comprises a series of individual statements that prompt answering on a scale from 1 to 5 . The 'Measuring impact' area is interesting for the purpose of this book, although there is no mentioning of the university's 'region' or any other surrounding territory. The six statements in this particular area are:

The university regularly assesses ...

... the impact of its entrepreneurial agenda;

... how its personnel and resources support its entrepreneurial agenda;

... entrepreneurial teaching and learning across the institution;

... the impact of start-up support;

... knowledge exchange and collaboration;

... the institution's international activities in relation to its entrepreneurial agenda.

Although HEInnovate tends to apply a narrow focus on a university's entrepreneurial agenda, it emphasises the importance of periodic monitoring and as an analytical tool to help understand aspects of its organisational performance and strategic management with regard to innovation impact. Unfortunately, HEInnovate does not help users to self-assess the 'how, where and why' of RII potential or RII pathways, but its various areas and statements do offer guidance as to which general characteristics are relevant components in an RII analytical framework.

Synthesising and summarising the above sources, we grouped most of the RII relevant functions into four large 'RII portfolio domains' that may exist within universities to create, support or enhance its regional innovation impact:

- Regional orientation, strategic development and knowledge infrastructure;

- Education and human resources development; 
- Research, technological development and knowledge transfer;

- Support to enterprise development and entrepreneurship.

The RII resources, activities, and pathways in these four domains may help to identify important factors within the university, and its home region, to better understand how a university's (tapped or untapped) RII potential may evolve into RII success. Naturally, these broad domains will partially overlap, interact, and perhaps also reinforce each other. The scale, scope and RII potential of these four domains will differ in each university and may change over time. Some domains, notably 'education and human resources development', will have a relatively large impact in the local socio-economic environment or spill-over effects in neighbouring regions, whereas 'research, technological development and knowledge transfer' may have national or even international impact in business sectors (Valero and Van Reenen, 2019).

Chapters 5 to 8 in Part II of this book elaborate on each of these four domains, presenting illustrative information on the RII potential and RII performance from RII self-reporting by universities in Europe. 